\title{
ESTRUTURA, CONDUTA E DESEMPENHO DA INDÚSTRIA DE MASSAS ALIMENTÍCIAS DO RIO GRANDE DO SUL (2001 - 2007)
}

\section{STRUCTURE, CONDUCT AND PERFORMANCE OF THE INDUSTRY OF PASTA OF RIO GRANDE DO SUL (2001 - 2007)}

\author{
Vitor Francisco Dalla Corte ${ }^{1}$; Pascoal José Marion Filho ${ }^{2}$ \\ ${ }^{1}$ Universidade Federal do Rio Grande do Sul - UFRGS - Porto Alegre - Brasil \\ vitordallacorte@gmail.com \\ ${ }^{2}$ UniversidadeFederal de Santa Maria - UFSM - Santa Maria - Brasil \\ pascoaljmarion@yahoo.com.br
}

\begin{abstract}
Resumo
A pesquisa avalia a estrutura, conduta e desempenho da indústria de massas alimentícias do Rio Grande do Sul no periodo de 2001 a 2007. Utiliza-se como base teórica na análise o modelo estrutura-conduta-desempenho (ECD) e as estratégias de Porter e Mintzberg. Os resultados para a estrutura da indústria mostram que: a concentração cai, a produção é diversificada e diferenciada e existem barreiras à entrada importantes para os ingressantes no setor, como a capacidade ociosa das empresas instaladas, o valor do capital inicial e o acesso aos canais de comercialização. Na conduta, adiferenciação e a qualidade são as mais utilizadas. O desempenho da indústria está piorando, mesmo com o aumento na produção, uma vez que a lucratividade está em queda e as empresas estão perdendo participação no mercado.
\end{abstract}

Palavras-chave: indústria de massas alimentícias; estratégias; estrutura industrial.

\section{Introdução}

As últimas duas décadas do século XX e início do século XXI foram palco de grandes transformações no ambiente econômico e social mundial. Segundo Castells (1999), uma nova economia surgiu em escala global, transformando a sociedade em sua concepção, resultado de uma revolução informacional que exige dos atores sociais, principalmente das empresas, uma nova conduta.

Este novo ambiente trouxe às empresas nacionais uma série de dificuldades, pois estas tiveram que se adaptar a um novo cenário concorrencial, desencadeado principalmente pela abertura dos mercados no início da década passada. O termo reestruturação produtiva passou, a partir daí, a ser comum em trabalhos acadêmicos, visando demonstrar a preocupação das empresas atuais no sentido de se adaptarem ao novo ambiente e, desta forma, atingir elevados níveis de 
competitividade, fator que se tornou não só a chave do sucesso para as organizações, mas também o fator determinante de sua sobrevivência no mercado.

Atualmente, as massas alimentícias (ou macarrão) estão entre os alimentos mais conhecidos em todo o planeta, sendo o Brasil um dos grandes produtores e consumidores em nível mundial. Segundo dados da Associação Brasileira das Indústrias de Massa Alimentícias - ABIMA (2007), a produção brasileira de macarrão no ano de 1994 foi de 780 mil toneladas e chegou em 2007 a 1.220 mil toneladas. Com o aumento na produção, em 2007 o Brasil passou a ocupar o terceiro lugar entre os maiores produtores mundiais de massas alimentícias, atrás somente da Itália e dos Estados Unidos.

O Rio Grande do Sul é o $3^{0}$ maior produtor de massas alimentícias do Brasil. A sua expressão na fabricação do produto e as mudanças ocorridas no ambiente econômico mundial e nacional justificam a pesquisa, já que afetaram acadeia produtiva de massas, especialmentea partir do fim da regulamentação e da queda de barreiras tarifárias e não-tarifárias para importação de trigo e de massas. Por isso, tem-se como objetivo avaliar a estrutura, conduta e desempenho da indústria.

$\mathrm{O}$ artigo está estruturado em cinco seções, sendo esta introdução a primeira delas. A segunda seção traz a teoria utilizada na pesquisa, o modelo ECD e as estratégias de Porter e Mintzberg. Na seqüência, apresentam-se à metodologia e a fonte de dados. Na quarta seção, analisa-se a estrutura, conduta e desempenhoda indústria de massas alimentícias do Rio Grande do Sul. Por fim, na quinta seção, apresentam-se as conclusões da pesquisa.

\section{O modelo ECD e as estratégias de Porter e de Mintzberg}

Nesta seção, apresentam-seos referenciais teóricosutilizados na pesquisa, o modelo ECD (estrutura - conduta - desempenho) e as estratégias de Porter (1980) e de Mintzberg (1988).

\subsection{O modelo estrutura-conduta-desempenho (ECD)}

O modelo ECD é oriundo da Organização Industrial (OI) e, segundo Farina (1997), serve para determinar as forças responsáveis pela organização da indústria e como estas têm se alterado no tempo. O modelo visava inicialmente avaliar a relação entre concentração e lucratividade dos oligopólios, objetivando auxiliar na política antitruste dos EUA. Admitia-se que quanto mais concentrado o mercado, maior a possibilidade de ocorrer uma coalizão tácita entre as empresas para maximização conjunta dos lucros, o que resultaria em uma prática semelhante à de um monopólio, trazendo, desta forma, prejuízos para a sociedade.

O relacionamento da estrutura de mercado com o desempenho no modelo, passando pela conduta das empresas e assumindo um sentido de causalidade da primeira para a última, deriva dos modelos de concorrência perfeita e monopólio. De acordo com a teoria econômica neoclássica, a 
empresa monopolista maximizadora de lucros produz menos, obtém maior lucro e pratica preços mais elevados do que a empresa que atua no mercado de concorrência perfeita, o que é ruim para a sociedade.

Com o passar do tempo, o modelo ECD passou por várias formalizações e abandonou o sentido de causalidade unidirecional, que segue da estrutura para o desempenho, sendo a primeira determinada exogenamente. Segundo Porter (1980), vários modelos têm explorado aspectos da empresa em um caráter dinâmico, considerando que todo o sistema evolui constantemente em função de mudanças internas e externas a ele, o que permite que tais modelos forneçam respostas mais completas e favoráveis em relação aos objetivos pretendidos.

Sobre o sentido de causalidade, Scherer e Ross (1990) afirmam que existem importantes efeitos de feedback entre as variáveis do modelo. Como exemplo cita que grandes esforços de pesquisa e desenvolvimento (variável da conduta) realizados por uma firma podem alterar a tecnologia predominante na indústria, a estrutura de custos e o grau de diferenciação física do produto. Outro exemplo citado, é que políticas de determinação de preços podem encorajar a entrada de novas firmas no mercado ou expulsar firmas mais fracas, conseqüentemente alterando a estrutura de mercado.

A seguir, apresentam-se os componentes do modelo estrutura-conduta-desempenho e as suas variáveis, exceto as relacionadas às políticas públicas e condições básicas da oferta e da demanda, por não ser objeto de pesquisa.

\subsubsection{A estrutura de mercado}

Para Resende e Boff (2002), a estrutura de mercado desempenha um importante papel dentro do modelo ECD. Entretanto, Leite (1998) destaca que o termo tem três sentidos diferentes. $\mathrm{O}$ primeiro refere-se às características mais aparentes do mercado, que é definido conforme o número de empresas concorrentes entre si e pela oferta de produtos diferenciados ou homogêneos; o segundo ponto de vista diz respeito ao modelo estrutura-conduta-desempenho, onde as características das firmas estão relacionadas a varáveis como concentração, barreiras à entrada, bens substitutos, dentre outras. Já a terceira maneira de se enfocar estrutura é semelhante ao segundo ponto de vista, contudo, acrescendo-se aspectos que dão um sentido de dinâmica.

Leite (1998) menciona que a estrutura engloba características de organização do mercado e que a mesma influencia estrategicamente a natureza da competição e os preços dentro deste. De acordo com Carlton e Perloff (1990), a estrutura de mercado pode ser definida analisando as seguintes variáveis: número de vendedores/ compradores (concentração), barreiras à entrada, integração vertical, diferenciação do produto e diversificação da produção. 
A concentração é um indicador sintético da concorrência existente em um mercado. Para Kon (1994), a medida dá os elementos empíricos necessários para essa avaliação e serve também para comparações intertemporais, o que permite examinar a dinâmica do mercado do lado da oferta.

Farina (1993) lembra que o conceito de concentração não se refere apenas ao número de participantes de um dado mercado; mais do que isto, se refere ao controle de uma grande proporção de uma determinada atividade econômica por uma pequena proporção dos participantes nesta atividade. Sobre a sua quantificação, Kon (1994) afirma que normalmente são utilizados indicadores que seguem três critérios, que são: a capacidade produtiva, o número de empregados e os ativos possuídos. A capacidade produtiva pode estar relacionada à quantidade física de produção ou a valores monetários (valor das vendas, valor adicionado etc.). O número de empregados é normalmente utilizado para mensurar o poder das empresas pela maior facilidade de obter informações. Contudo, esta medida é influenciada pelas técnicas empregadas, pelo grau de integração e pelo nível de automatização das diferentes firmas.

As medidas mais utilizadas para quantificar a concentração em uma indústria, segundo Kon (1994), são a razão de concentração (Cr) e o índice Herfindahl-Hirschman (HH). A Razão de concentração $(\mathrm{Cr})$ mede a proporção da indústria de posse das $k$ maiores empresas, tomando-se como base o indicador escolhido (vendas, número de empregados, ativos etc.). Seu cálculo é dado por:

$$
\operatorname{Cr}(\mathrm{k})=\sum \quad \mathrm{Pi}
$$

Sendo:

$k=$ número das maiores empresas que fazem parte do cálculo ( 4,8 etc.); e

$\mathrm{Pi}=$ participação percentual da i-ésima empresa no mercado.

Esta medida é de fácil interpretação e indica à participação no mercado (concentração) das $k$ maiores empresas que formam a indústria, sendo o máximo 100\% (monopólio).

O Índice de Herfindahl-Hirschman (HH) é definido pela soma dos quadrados da participação percentual de cada empresa em relação ao tamanho total da indústria. Este índice leva em conta todas as empresas da indústria e é calculado pela fórmula apresentada a seguir:

$$
\mathrm{HH}=\sum \quad \mathrm{Pi}
$$

Sendo:

$n$ : número de empresas da indústria atuantes no mercado; e

Pi: participação percentual da i-ésima empresa no mercado. 
Este índice assume o valor máximo de 10.000 (se o Pi estiver em percentagem), quando existe apenas uma empresa na indústria (monopólio). O índice assume seu menor valor (10.000/n) quando as empresas têm participação igualitária no mercado. $\mathrm{O}$ valor de $\mathrm{HH}$ aumenta conforme aumenta a desigualdade entre as empresas pertencentes à indústria, apresentando-se, desta forma, como um bom indicador da situação de mercado. Convém salientar que o tamanho da empresa é levado em conta pela sua participação ao quadrado(Pi), ou seja, as empresas menores contribuem menos que proporcionalmente para o valor do índice. Desta forma, quanto maior o índice, mais concentrado é o mercado e, conseqüentemente, menor a concorrência entre as empresas.

Segundo Usdoj (1997), o mercado não é concentrado quando o valor do índice HH estiver abaixo de 1.000; tem concentração moderada quando se situar no intervalo entre 1.000 e 1.800; e é altamente concentrado quando atingir valor superior a 1.800 .

As demais variáveis da estrutura, como barreiras à entrada, integração vertical, diversificação da produção e diferenciação do produto, também são avaliadas para se conhecer a organização da indústria e a sua dinâmica.

As barreiras à entrada, variável da estrutura, são importantes determinantes da conduta e do desempenho da indústria, já que a sua presença, no longo prazo, oportuniza a prática de preços acima do nível competitivo (CARLTON; PERLOFF, 1990). Elas também servem de base para a reação de firmas já estabelecidas frente à entrada de novos concorrentes, uma vez que indicam a extensão na qual elas podem elevar seus preços de venda sem induzir a entrada de novos concorrentes na indústria (BEM, 1991).

Segundo Marion Filho (1997), as barreiras à entrada citadas com maior freqüência na literatura econômica são: economias de escala, necessidade de capital, acesso aos canais de distribuição, desvantagens de custos independentes de escala, produto diferenciado e política pública (regulação). Servem como exemplo de barreiras à entrada: o valor do investimento inicial; os acessos à tecnologia e à matéria-prima; a escala mínima de produção para entrar na indústria; a qualificação da mão-de-obra; a ociosidade das empresas instaladas; a dificuldade de colocar o produto no mercado e outras barreiras aqui não especificadas.

A integração vertical pode ser caracterizada como a expansão da indústria além de seu mercado de atuação, podendo esta ser para trás (da indústria para seus fornecedores de matériasprimas e demais insumos) ou para frente (da indústria para os distribuidores). Esta pode ser uma forma de se reduzir custos, assim como proporcionar aos produtores um maior controle sobre o seu ambiente econômico, visto que firmas integradas podem estabelecer uma estrutura de preços verticais, restringindo as margens de lucro dos seus competidores menos integrados (BEM, 1991).

Cabe ainda destacar a diversificação da produção e a diferenciação do produto como variáveis estruturais. Segundo Kon (1994), entende-se por diversificação a introdução de um 
produto em um mercado no qual a firma ainda não participa. Nesse sentido, uma empresa tem produção diversificada quando atua em mais de um mercado. Já a diferenciação do produto pode ser entendida como a introdução de uma nova mercadoria para um mesmo mercado, que tenha a característica de ser substituta próxima de outra anteriormente por ela produzida.

\subsubsection{A conduta das empresas}

O segundo conceito do modelo ECD a ser apresentado é o da conduta. Para Bem (1991),ele pode ser expresso como o comportamento das firmas no mercado em relação a preços, produção, características do produto, pesquisa e desenvolvimento (P\&D) e propaganda. Além disso, ela é responsável por estabelecer um elo entre a estrutura e o desempenho.

Assim, a conduta consiste nas políticas da empresa em relação ao mercado concorrencial em

que a empresa se encontra, seja esta uma política efetiva ou potencial. É avaliando a conduta da empresa que serão demonstradas as políticas de fixação de preços e produção, bem como a fixação de padrões de qualidade e políticas de ação ou coação da empresa (BEM,1991).

Para Leite (1998), a variável conduta é representada pelas estratégias competitivas adotadas pelas empresas quando se relaciona o modelo ECD à competitividade. A conduta de mercado diz respeito aos processos de decisão e as relações intra-industriais, bem como aos padrões de comportamento que as firmas assumem para se ajustar ou se adequar ao mercado no qual elas operam.

Existem amplas variações de condutas das empresas. No entanto, a maioria dos trabalhos empíricos tem como objetivo determinar a extensão em que os padrões de concorrência ou o comportamento estão associados à estrutura de mercado (determinante da conduta) e ao desempenho de mercado (determinado pela conduta).

Nesta pesquisa, considera-se como conduta os gastos com pesquisa e desenvolvimento (P\&D), a realização de contratos entre empresas e, de uma forma complementar, as estratégias genéricas de Porter (1980) e Mintzberg (1988), descritas a seguir.

\subsubsection{As estratégias competitivas de Porter}

Os primeiros ensaios acadêmicos sobre estratégia foram produzidos por docentes e discentes da Harvard Business School. Entre os vários estudos acadêmicos desenvolvidos por essa escola, destacam-se os da área de organização industrial (OI), a exemplo do modelo ECD (estrutura, conduta e desempenho).

Porter (1980) define estratégias competitivas como ações ofensivas ou defensivas para criar uma posição defensável em uma indústria e assim enfrentar as forças competitivas. Genericamente, segundo Porter (1986), pode-se utilizar como formas de competição no mercado a liderança em 
custo (obter uma vantagem sustentável em termos de custo sobre os demais competidores e utilizála como forma de vender produtos a um preço mais baixo), a diferenciação (atender a preferências dos consumidores que não possam ser satisfeitas por um bem padronizado) e o enfoque (ou nicho de mercado, em que os clientes possuem preferências ou exigências únicas).

Porter (1986) também afirma que a empresa que aplica apenas uma das estratégias genéricas apresenta melhor desempenho. As empresas que procuram adotar uma estratégia híbrida ou que fracassam na busca por uma das estratégias foram por ele designadas como stuck-in-themiddle(expressão traduzida para o português como meio-termo). O fato de uma empresa ser classificada como "meio-termo"não significa que ela não emprega métodos e armas competitivas típicas de uma ou mais das estratégias genéricas, mas apenas que a sua estratégia como um todo carece de consistência interna (DESS; DAVIS, 1984 apud SILVA; CARNEIRO; CAVALCANTI, 2003).

Vários estudos sobre estratégia empresarial foram desenvolvidos utilizando as tipologias de Porter (1980), como comprova a revisão de literatura de Miller e Dess (1993). Os autores selecionaram artigos publicados no Journalof Management Studies entre 1986 e 1990 e constataram que o trabalho de Porter - Estratégia Competitiva - foi citado, aproximadamente, na metade dos artigos, demonstrando a proliferação e aceitação das idéias do autor.

\subsubsection{Estratégias competitivas de Mintzberg}

Mintzberg (1988) entende que a maioria das estratégias explicitadas na literatura são falhas, pois focam de forma muito estreita alguns tipos especiais ou propõem agregações arbitrárias. Por isso, o autor propôs novas tipologias de estratégias genéricas a partir do conceito de diferenciação, com detalhamento maior do que o apresentado nas estratégias de Porter (1980).

Segundo Silva, Carneiro e Cavalcanti (2003), as estratégias genéricas de Mintzberg (1988) podem ser definidas como:

- Diferenciação por qualidade: a estratégia se caracteriza pela oferta de um produto melhor do que o dos concorrentes, embora não fundamentalmente diferente (maior confiabilidade, maior durabilidade ou desempenho superior);

- Diferenciação por design (projeto): ocorre quando se oferece um produto diferente do apresentado pela concorrência. A diferença básica desta estratégia para aquela de diferenciação por qualidade é que a diferenciação por design busca efetivamente oferecer algo diferentee não simplesmente ou necessariamente melhor;

- Diferenciação por suporte: existe quando é oferecido algo mais junto com o produto. Em geral, a ampliação do nível de serviços agregados (prazo de entrega menor, financiamento à venda, assistência técnica etc.) ou a oferta de produtos complementares; 
- Diferenciação por imagem: ela se caracteriza pelo desenvolvimento da imagem do produto, tornando-o distinto dos demais. Esta imagem pode ser criada através da propaganda, como também através de técnicas de promoção, apresentação, ou pela inclusão de detalhes que deixam o produto mais atrativo;

- Diferenciação por preço: a estratégia é cobrar um preço mais baixo pelo produto. Se os demais atributos do bem forem iguais ou não muito diferentes dos de seus concorrentes, os consumidores tenderão a preferir aquele que exibir um preço mais baixo. Mintzberg insiste em afirmar que diferenciação por preço não é o mesmo que a minimização de custo de Porter. Isto porque a minimização de custo só se caracteriza como vantagem competitiva caso se traduza em menor preço no mercado (caso fosse visível para o consumidor);

- Não-diferenciação: essa estratégia se baseia no fato de que é possível copiar as ações de outras empresas, desde que o mercado ofereça espaço para produtos concorrentes e a empresa se especialize em acompanhar e imitar os lançamentos dos concorrentes, apoiando seus próprios lançamentos com ações inovadoras e eficientes de marketing. A estratégia de não-diferenciação assemelha-se ao conceito de meio-termo desenvolvido por Porter (1980). Entretanto, duas diferenças merecem destaque em relação ao modelo de Porter: $1^{\text {a }}$ ) Mintzberg considera que a estratégia pode ser desenvolvida explicitamente, enquanto Porter considera o meio-termo como um tipo residual, resultante da implementação inadequada ou ineficiente de uma das estratégias genéricas puras; $2^{\mathrm{a}}$ ) ao contrário do que Porter supõe para o meio-termo, Mintzberg não condena a estratégia a um desempenho inferior ao das demais estratégias.

Neste estudo, utiliza-se a conduta do modelo ECD e as estratégias de Porter (1980) e de Mintzberg (1988) como complementares, visando identificar os diferentes posicionamentos das empresas produtoras de massas alimentícias, mesmo que elas não adotem um posicionamento único em relação às estratégias competitivas. A seguir descreve-se o desempenho, último componente do modelo ECD analisado na pesquisa.

\subsubsection{O Desempenho das empresas}

Os resultados obtidos pelas empresas caracterizam o desempenhoda indústria. Segundo Scherer e Ross (1990), o mesmo é conseqüência da conduta adotada pelos gestores, condicionada pela estrutura existente no mercado onde atuam.Segundo os autores, na análise do desempenho industrial devem-seavaliar os resultados ex-post facto. Neste sentido, os trabalhos empíricos concentram-se nos resultados financeiros, sendo a lucratividade uma das variáveis mais utilizadas.

A lucratividade é muitas vezes relacionada ao grau de concentração das empresas no mercado. Contudo, esta afirmação pode ser difícil de ser comprovada, porque muitas vezes o lucro pode ser resultado de outras fontes, tais como mudanças inesperadas na relação entre a demanda e 
os custos. Apesar disso, quando os lucros excessivos são mantidos por um longo período de tempo, são persistentes, só podem ser explicados pela existência do poder de mercado.

De acordo com Scherer e Ross (1990), o bom desempenho é multidimensional e engloba os seguintes elementos:

a) As decisões sobre o que, quanto e como produzir devem ser eficientes, ou seja, os recursos escassosnão devem ser desperdiçados e as decisões de produção devem corresponder qualitativa e quantitativamente à demanda dos consumidores;

b) As operações dos produtores devem ser progressivas, tirando vantagem das oportunidades abertas pelaciência para aumentar o output por unidade de input e fornecer aos consumidores novos produtos superiores;

c)As operações dos produtores devem facilitar o emprego total de recursos, em especial os recursos humanos;

d) A distribuição de renda deve ser eqüitativa, o que implica que a remuneração dos produtores não seja excessiva.

Segundo Bem (1991), a evolução dos preços também é uma variável importante do desempenho da indústria, uma vez que a amplitude na mudança reflete as margens de lucro das empresas.

Vê-se que diversas variáveis podem ser utilizadas para avaliar o desempenho. No entanto, utiliza-se neste trabalho como variáveis o preço dos produtos, a quantidade e a lucratividade das empresas, destacadas na metodologia.

\section{Metodologia e fonte de dados}

Nesta seção, apresenta-se a metodologia da pesquisa, mais especificamente o conjunto de variáveis utilizadas para avaliar os componentes do modelo ECD (estrutura, conduta e desempenho) da indústria de massas alimentícias do Rio Grande do Sul, e a origem dos dados utilizados na análise.

\subsection{A metodologia da pesquisa}

A forma utilizada para avaliar cada variável do modelo ECD, componentes estrutura, conduta e desempenho,é descrita a seguir.

\subsubsection{Variáveis da estrutura da indústria}

- Concentração: duas medidas são utilizadas para determinar a concentração da indústria, a razão de concentração $(\mathrm{Cr})$ e o índice Herfindahl-Hirschman $(\mathrm{HH})$. A razão de concentração $(\mathrm{Cr})$ é determinada a partir da participação de mercado das quatro maiores empresas, ordenadas 
pelofaturamento e pelo número de empregados nos anos de 2002, 2004 e 2006. Com relação ao índice $\mathrm{HH}$, utiliza-se como variável o número de empregados na indústria nos anos de 2001 e 2006;

- Barreiras à entrada: representam os empecilhos enfrentados por uma empresa ao tentar entrar em uma determinada indústria. Para análise, considera-se o valor do investimento inicial, o acesso à tecnologia de produção, a dificuldade na obtenção da matéria-prima, a escala mínima de produção, a exigência de mão-de-obra especializada, a capacidade de produção das empresas já instaladas e a dificuldade em colocar os produtos no mercado;

- Diferenciação do produto: a diferenciação do produto é avaliada a partir do "mix" de massas alimentícias ofertadas pelas empresas;

- Diversificação da produção: é determinada a partir da atuação da empresa em outros mercados, como por exemplo, na produção de biscoitos, pães etc;

- Integração vertical: a integração vertical pode ser feita para trás, em direção a fonte de matéria-prima, ou para frente, em direção ao varejo. Na pesquisa, verifica-se se o produtor de massas alimentícias também atua na produção de farinha de trigo e/ou na distribuição.

\subsubsection{A conduta}

- Propaganda (imagem): considera-se como propaganda qualquer gasto incorrido pelas empresas com o objetivo de divulgar seus produtos. Verifica-se também à evolução dos gastos e a proporção em relação ao faturamento;

- Pesquisa e desenvolvimento de produtos $(\mathrm{P} \& \mathrm{D})$ :avalia-se o montante gasto pela empresa em P\&D, a evolução dos gastos e a proporção que eles representam do faturamento;

- Custos, diferenciação e enfoque: identificam-se as opções adotadas pelas empresas participantes da pesquisa quanto às estratégias de Porter de reduzir custos, diferenciar produtos ou enfoque específico para nichos de mercado;

- Modo de fixação dos preços: busca-se identificar o poder na definição do preço dos produtos da empresa e a posição destes entre os praticados pelos concorrentes.Neste sentido, a pesquisa avalia se o preço é fixado pelo fabricante, pelo comprador ou se a empresa adota preço de mercado. Além disso, procura-se estabelecer a posição destes preços entre os existentes no mercado (se ele fixado abaixo, igual ou supera o dos concorrentes);

- Acordos e contratos entre as empresas: considera-se a existência de acordos formais e informais entre as empresas das indústrias, bem como a finalidade;

- Fusões e Aquisições:verifica-se a ocorrência de fusões e/ou aquisições de empresas na indústria; 
- Qualidade:investiga-se a adoção de algum sistema de controle de qualidade do produto, bem como se a empresa possui certificação;

- Suporte:considera-se suporte oferecer maior prazo para pagamento ou menor prazo de entrega do produto;

- Não-diferenciação: avalia-se se as empresas lançam produtos similares aos já existentes, emitam o que existe no mercado, ou inovam.

\subsubsection{Desempenho de mercado}

- Lucratividade: determina-se a evolução da lucratividade das empresasno período de 2002 a 2006. Por lucratividade entende-se o lucro líquido da empresa em relação ao total do faturamento;

- Evolução dos preços - avalia-se a evolução dos preços médios de mercado dos principais produtos da indústria;

- Evolução da produção física:é determinada a partir da quantidade produzida dos principais produtos da indústria no período de 2002 a 2006.

\subsection{Os dados da pesquisa}

$\mathrm{Na}$ análise, utilizam-se dados primários e secundários. Os dados primários foram coletados através da aplicação de um questionário estruturado nas empresas produtoras de massas alimentícias do Rio Grande do Sul. Este questionário assemelha-se aos já aplicados por Zaeyen (1986), Moraes (1996) e Marion Filho (1997).

Antes do envio, fez-se um pré-teste em duas empresas da indústria e alguns ajustes em relação aos termos técnicos utilizados. Em seguida, fez-se o contato telefônico e o envio dos questionários para os gestores das empresas que faziam parte do cadastro industrial da Federação das Indústrias do Rio Grande do Sul (FIERGS) no ano de 2007 (total de 42 empresas). Com o objetivo de ampliar a relação, verificou-se a relação das empresas filiadas a Associação Brasileira das Indústrias de Massas Alimentícias (ABIMA). Constatou-se que todas as empresas filiadas a ABIMA constavam no cadastro industrial da FIERGS, fato este que explica a utilização do cadastro da FIERGS (2007) como referência, pois engloba um número maior de empresas.

Apesar dos esforços realizados para obter informações sobre a indústria de massas alimentícias, das 42 empresas contatadas 14 responderam (33,33\%). No entanto, as empresas respondentes são representativas na população, pois utilizavam mais de $67 \%$ do total de empregados efetivos e faturaram mais de $70 \%$ do total da indústria no ano de 2007 . Mesmo assim, deve-se lembrar que esta a amostra é não probabilística. 
Os dados secundários foram obtidos junto a ABIMA, no Cadastro Industrial da FIERGS dos anos de 2002 e 2007 e na bibliografia.

\section{Estrutura, conduta e desempenho da indústria de massas}

A indústria de massas alimentícias do Rio Grande do Sul utiliza em sua grande maioria farinha de trigo nacional (75\%) e possui $15 \%$ da capacidade instalada nacional (ABIMA, 2007). Além disso, ela está concentrada em três regiões do Estado, Serra (39\%), Metropolitana Delta do Jacuí (20\%) e Vale dos Sinos (14\%).

O principal destino da produção de massas é o próprio Estado, já que os dados da pesquisa revelaram que $88 \%$ das vendas são para o Rio Grande do Sul e o restante $12 \%$ é vendida para outros estados. Logo, segundo os produtores, atualmente não está havendo exportação de massas alimentícias pelos produtores gaúchos. O principal canal de comercialização de massas no Rio Grande do Sul é a venda direta para as lojas de varejo por vendedores da empresa, $75 \%$ das vendas.

Esta seção traz a avaliação da estrutura, da conduta e do desempenho da indústria de massas alimentícias do Rio Grande do Sul. As estratégias de Porter e de Mintzberg complementam a tipificação da conduta.

\subsection{A estrutura da indústria}

A estrutura da indústria é avaliada a partir da concentração na indústria, das barreiras à entrada no setor, da diferenciação do produto, da diversificação da produção e da integração vertical.

\subsubsection{A concentração na indústria de massas alimentícias}

A evolução da concentração na indústria de massas alimentícias do Rio Grande do Sul pode ser vista na Tabela 1, onde está a razão de concentração $(\mathrm{Cr})$ das quatro maiores empresas para os anos de 2002, 2004 e 2006. Os dois indicadores utilizados (faturamento e número de empregados) indicam que a concentração na indústria vem declinando, pois, no ano de 2002, o CR4 em relação ao faturamento foi de 72,31\% e no ano de 2006 caiu para 48,67\%. O mesmo ocorreu com o CR4 em relação ao número de empregados, reduziu de 67,38\% em 2002 para 45,41\% em 2006.

Tabela 1 - A razão de concentração (Cr) e o índice de Herfindahl-Hirschman $(\mathrm{HH})$ da indústria de massas do Rio

Grande do Sul

\begin{tabular}{ccccc}
\hline & \multicolumn{3}{c}{$\mathbf{C r 4}(\mathbf{\%})$} & \\
\cline { 2 - 4 } Ano & Faturamento & $\mathbf{N}^{\mathbf{0}}$ de empregados & Índice HH \\
\hline 2001 & - & - & 1666,03 \\
2002 & $72,31 \%$ & $67,38 \%$ & - \\
2004 & $58,35 \%$ & $55,33 \%$ & -
\end{tabular}


A queda da concentração na indústria pode é explicada, em parte, pela saída de um dos grandesfabricantes do mercado e pela venda de uma grande empresa, que foi reestruturada e teve uma redução no marketshare de 25,02\% em 2004 para 7,25\% em 2006.

O índice HH confirma a redução na concentração da indústria de 2001 para 2006 e sugere que a concorrência se intensificou no mercado. Além disso, verifica-se que o índice é relativamente baixo em $2006(849,18)$ e está muito distante do nível máximo de concentração $(10.000)$. Adotando-se a classificação sugerida por Usdoj (1997), pode-se dizer que a indústria de massas alimentícias do Rio Grande do Sul passou de uma concentração moderada (localizada entre 1000 e 1800) para uma não concentrada (inferior a 1000).

\subsubsection{Barreiras à entrada na indústria}

Os produtores de massas consideram como principais barreiras à entrada na indústria, em ordem de importância, a capacidade de produção das empresas já instaladas, o valor do investimento inicial e a dificuldade de colocar o produto no mercado (ver Tabela 2).

A capacidade de produção das empresas já instaladas está diretamente ligada ao tamanho das empresas, a escala de operação, o que acaba inibindo a entrada de outras empresas no setor.

$\mathrm{O}$ valor do investimento inicial é uma barreira associada à necessidade crescente de capital para se produzir em larga escala. Além disso, o investimento exigido nesta indústria é altamente específico, pois exige maquinário diferenciado, que dificilmente pode ser reempregado para a produção de outro bem que não seja o de massas alimentícias. De maneira geral, esse tipo de barreira à entrada esta presente na maioria das indústrias intensivas em capital.

Tabela 2 - Notas médias atribuídas pelos fabricantes de massas às barreiras à entrada de firmas na indústria em 2007

\begin{tabular}{cc} 
Barreiras à entrada & $\begin{array}{c}\text { Notas médias } \\
(0-10)\end{array}$ \\
\hline Capacidade de produção das empresas já instaladas & $\mathbf{8 , 6 7}$ \\
Valor do investimento inicial & $\mathbf{8 , 5 0}$ \\
Dificuldade em colocar o produto no mercado & $\mathbf{8 , 1 7}$ \\
Exigência de mão-de-obra especializada & 5,83 \\
Conhecimento exigido para produzir (fórmulas e processos) & 5,67 \\
Quantidade mínima de produção & 4,67 \\
Dificuldade na obtenção de matéria-prima & 3,83 \\
Acesso à tecnologia de produção (máquinas) & 3,33 \\
\hline
\end{tabular}

Fonte: Pesquisa de campo (2007)

Também é considerada barreira à entrada na indústria o acesso aos canais de comercialização, ou seja, ao varejo. Segundo dados da ABIMA (2007), 93,5\% das vendas de 
massas alimentícias no Brasil em 2005 estavamconcentradas no varejo. Esta concentração de vendas no varejo pode estar atrelada, segundo Ipea (1998), as transformações recentes no sistema de distribuição de alimentos, com o aumento de relevância de canais curtos de distribuição, como hiper e supermercados, bem como franquias.

As demais barreiras à entrada pesquisadas receberam dos gestores notas médias relativamente baixas, desqualificando-as como barreiras importantes.

\subsubsection{Diferenciação do produto, diversificação da produçãoe integração vertical}

O mercado de massas pode ser dividido em três categorias, massas secas, massas frescas e massas instantâneas.

Dentro da categoria de massas secas existem as massas padre nosso, estrelinha, argolinha, ave-maria, conchinha, espaguete, furadinho, fuzile, talharim, rigatone, ninhos, penne, entre outras.

$\mathrm{Na}$ categoria de massas frescas, podem-se citar as massas para pizza, pastéis e alguns tipos já citados acima, só que não secas. Este tipo de massa requer refrigeração e a sua perecibilidade é alta.

A categoria de massas instantâneas tem menor tempo de cozimento e geralmente é a de mais fácil preparo. Logo, as massas secas diferenciam-se das massas frescas devido a este fator, o tempo de cozimento.

A distribuição da produção de massas no Rio Grande do Sul entre as categorias pode ser visualizada na Tabela 3.

Tabela 3 - Divisão da produção de massas alimentícias no Rio Grande do Sul em 2007

\begin{tabular}{cc}
\hline Divisão da produção de massas alimentícias & Percentual \\
\hline Massas alimentícias secas & $71,28 \%$ \\
Massas alimentícias frescas & $28,72 \%$ \\
Massas alimentícias instantâneas & $00,00 \%$ \\
\hline
\end{tabular}

Fonte: Pesquisa de campo (2007)

Verifica-se na tabela que a principal produção de massas alimentícias é a de massas secas (71,28\%), seguida da produção de massas frescas (28,72\%). Nenhum dos respondentes da pesquisa informou que produzia massas instantâneas, o que deixa os produtores de massas do Estado limitados aos mercados de maior concorrência e de menor expansão no Brasil, segundo ABIMA (2007). Este fato pode ser explicado pelo maior investimento que uma linha de produção de massas alimentícias instantâneas requer quando comparado ao investimento em uma linha de produção de massas secas ou frescas, pois o primeiro exige um pré-cozimento do macarrão antes da secagem. 
Portanto, os produtores de massas alimentícias podem ofertar produtos de diferentes formatos, diferentes tempos de cozimento e diferentes utilizações. Logo, a diferenciação do produtoé elevada na indústria.

Com relação à diversificação da produção, a pesquisa detectou que ela também ocorre, uma vez que $8,33 \%$ das massas produzidas no Estado são preparadas (lasanhas, pizzas, nhoque etc.)e $36 \%$ das empresas atuam na produção de biscoitos, buscando maior faturamento e minimizar riscos para o negócio. Este fato pode ser explicado pela utilização no processo produtivo da mesma matéria-prima base, a farinha de trigo, e por similaridades no processo produtivo.

A integração vertical para frente e para trás é baixa, mas existente, na indústria de massas alimentícias. A integração vertical para trás ocorreem uma das 14 empresas que responderam a pesquisa, pois a mesma também produz farinha de trigo. Já a integração vertical para frente ocorre em $29 \%$ das empresas fabricantes de massas e se dá através de pontos próprios de venda direta ao consumidor.

\subsection{A conduta da indústria}

Segundo o modelo ECD, deve-se esperar que a estrutura da indústria influencie a conduta das empresas e seja influenciada pela mesma. Para avaliar a conduta das empresas na indústria de massas alimentícias do Rio Grande do Sul, utilizam-se como referenciais teóricos o modelo ECD e as estratégias competitivas de Porter (1980) e de Mintzberg (1988).

\subsubsection{Gastos em P\&D e contratos na indústria}

Os gastos em pesquisa e desenvolvimento (P\&D) podem contribuir para a redução de custos, aumento da qualidade do produto ou fabricação de produtos ainda não disponíveis no mercado. $\mathrm{Na}$ indústria, 36\% dos produtores afirmaram que investem em $\mathrm{P} \& \mathrm{D}$ e que gastam, em média, $0,7 \%$ das vendas nesta atividade.

No entanto, a produção de massas alimentícias depende fundamentalmente da quantidade e qualidade da farinha de trigo, e o insumo é um dos principais fatores para promover a segmentação do mercado e viabilizar estratégias de diferenciação do produto. Assim, surge a necessidade de farinhas com blendsespeciais. Para suprir esta demanda, contratos entre as empresas das indústrias de farinha de trigo e de massas alimentícias são realizados, sendo que 50\% dos produtores de massas alimentícias se utilizam de contratos. Em relação à compra, 36\% dos produtores de massas alimentícias afirmaram que sempre compram dos mesmos fornecedores. 


\subsubsection{As estratégias competitivas na indústria}

Ao utilizar as tipologias de Porter para análise das estratégias da indústria, verifica-se que a indústria vem utilizando a diferenciação como estratégia mais relevante (ver Tabela 4), seguida da estratégia de produção com o custo mais baixo. Já a produção para nichos específicos vem sendo pouco utilizada.

Entre às estratégias competitivas de Mintzberg (1988), verifica-se que as empresas consideraram a qualidade do produto como sendo a principal forma de diferenciação. Além disso, $85,71 \%$ delas afirmaram ser esse o seu grande diferencial competitivo e por isso adotam algum sistema de controle de qualidade. Entretanto, somente uma das quatorze empresas pesquisadas destacou possuir certificação (ISO 9001:2000).

Tabela 4 - Notas médias atribuídas às estratégias pelos produtores de massas alimentícias em 2007

\begin{tabular}{lcc}
\hline & Estratégias adotadas & $\begin{array}{c}\text { Nota média } \\
(\mathbf{0}-\mathbf{1 0})\end{array}$ \\
\hline \multirow{3}{*}{ Porter } & Produtos diferenciados & $\mathbf{8 , 3 4}$ \\
& Produção com o custo mais baixo & $\mathbf{8 , 0 0}$ \\
& Produção para nichos específicos & 4,00 \\
& Qualidade do produto & $\mathbf{9 , 6 6}$ \\
Oferecer algo diferente em relação ao design & 6,34 \\
Mintzberg & perecer serviços agregados como produtos complementares, maior prazo de & 6,34 \\
& Investimentos em propaganda & 5,66 \\
\hline Cobrar um preço mais baixo indiferente do custo de produção & 4,00
\end{tabular}

Fonte: Pesquisa de campo (2007)

A diferenciação por qualidade deve iniciar na triticultura, pois o trigo é a base para gerar determinadas matérias-primas especiais. Portanto, existe a possibilidade de incorporar novos produtos e de melhorar a qualidade, ampliando-se as relações ao longo da cadeia de produção, abrindo-se um espaço para uma maior integração entre os produtores de trigo, a indústria de farinha e os fabricantes de massas alimentícias, o que não ocorre no Rio Grande do Sul.

Como a indústria no Estado é caracterizada por possuir empresas produtoras de massas alimentícias de pequeno e médio porte (nenhuma empresa está entre as quatro maiores nacionais), explica-se a preocupação estratégica em custos, pois fica difícil a competição com grandes empresas, as quais negociam maior quantidade e melhor qualidade de farinha de trigo, podendo ofertar com vantagem um produto com preço mais baixo.

O design também foi citado como estratégia de diferenciação pelos produtores, ou seja, oferecer no mercado um produto com características distintas dos produtos concorrentes. A diferença básica entre a estratégia de diferenciação de qualidade e design, é que esta última consiste 
em oferecer algo diferentee não necessariamente melhor. Esta é uma alternativa para as empresas de menor porte, pois podem ousar em diferentes misturas, sabores, embalagens, adicionando características aos seus produtos.

Também é possível diferenciar o produto sem necessariamente alterar seus atributos intrínsecos, apenas oferecendo algo mais na venda. Em geral, é a ampliação do nível de serviços agregados (prazo de entrega menor, financiamento à venda, assistência de vendas) ou a oferta de produtos complementares, o que caracteriza uma estratégia de diferenciação por suporte. Segundo os respondentes da pesquisa, este tipo de estratégia tem a mesma relevância do design (média 6,34).

A estratégia de diferenciar o produto da empresa a partir do preço, como cobrar pelo produto ofertado um preço mais baixo, é pouca utilizada pelas empresas que participaram da pesquisa, pois $64,30 \%$ delas responderam que praticam preços um pouco acima da média

A estratégia de diferenciação por imagem, que é obtida a partir dos gastos com propaganda e promoção dos produtos, não foi considerada relevante pelos produtores. A seguir, analisa-se o desempenho da indústria de massas alimentícias.

\subsection{O desempenho da indústria}

$\mathrm{Na}$ avaliação do desempenho da indústria produtora de massas alimentícias do Rio Grande do Sul, utilizam-se como indicadores a lucratividade, os preços médios anuais e o volume de produção. A pesquisa de campo revelou que a lucratividade média dos produtores de massas alimentícias do Rio Grande do Sul caiu no período analisado, e no ano de 2006 a redução ocorreu em mais de $50 \%$ das empresas.

A queda na lucratividade da indústria pode ser explicada, pelo menos em parte, pelos preços médios de cada segmento da produção (ver Figura 1), pois a indústria gaúcha se concentra na produção de massas secas, que possuem menor valor agregado.

Figura 1 - Preços médios reais das massas secas, instantâneas e frescas

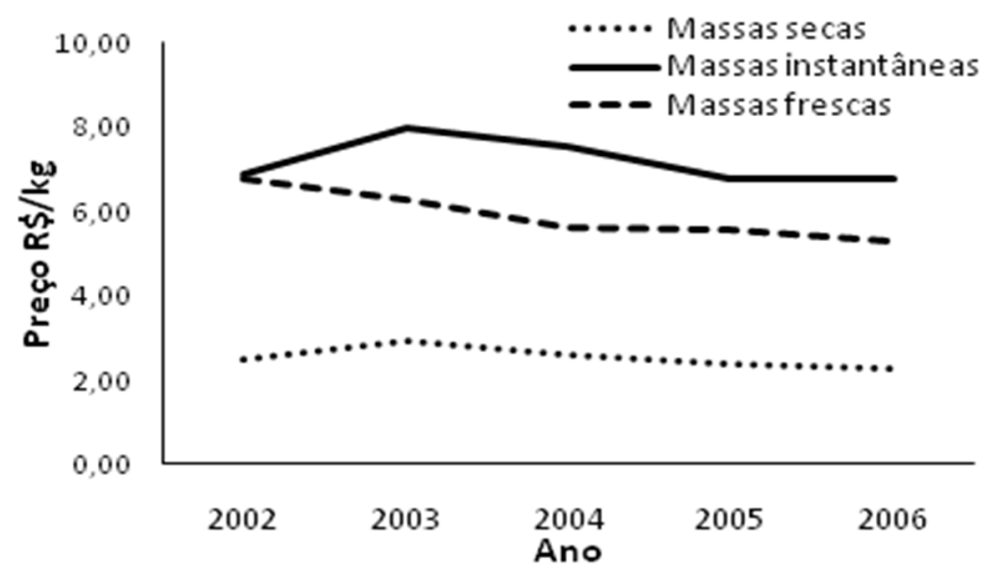

Fonte: Preços médios da ABIMA (2007) deflacionados pelo IGP-DI 
Comparando-se os preços médios das massas secas com os das massas instantâneas e frescas, constata-se que existe uma diferença importante entre eles. No ano de 2006, por exemplo, o preço das massas instantâneas superou o de massas secas em mais de $200 \%$ e o de massas frescas foi maior do que o de massas secas em 136\%. Em relação à evolução dos preços médios reais, tevese uma queda nos três segmentos, sendo mais acentuado no de massas frescas $(-21,16 \%)$, seguido pelo de massas secas $(-8,72 \%)$ e pelo de massas instantâneas (-1,51\%).

Segundo dados da ABIMA (2007), do consumo total de massas no Brasil em 2006, o de massas secas representava86,72\%, o de massas instantâneas 10,25\% e o de massas frescas 3,03\%. Embora o segmento massas secas tenha a maior fatia do mercado, de 2002 para 2006 ele cresceu $11,95 \%$, em quanto o de massas instantâneas se expandiu em 32,97\% e o de massas frescas aumentou em 19,35\%.

A maior concorrência no mercado pode ter sido uma das causas da piora no desempenho da indústria do Rio Grande do Sul, uma vez que a produção de massas no Estado aumentou de 167.123 toneladas em 2002 para 183.005 toneladas em 2006 (acréscimo de 9,50\%) e a produção nacional cresceu $14,02 \%$ no mesmo período. Com a menor expansão da indústria gaúcha, caiu a participação de mercado de 15,70\% em 2002 para 15,01\% em 2006. Os índices de concentração reforçam a idéia de aumento da concorrência no mercado, já que houve queda no Cr4 e no índice HH (ver subitem 4.1). Portanto, os indicadores de desempenho utilizados para a indústria, revelam que está ocorrendo uma perda de competitividade da indústria gaúcha.

\section{Conclusão}

O estudo avalia a estrutura, a conduta e o desempenho da indústria de massas alimentícias do Rio Grande do Sul. Os resultados da pesquisa mostram que a estrutura da indústria não é concentrada, possui poucas barreiras à entrada, gera produtos diferenciados e diversificados e tem baixa integração vertical, especialmente para trás.

A concentração da indústria está em queda, pois, pelo Cr4, caiu de 72,31\% em 2002 para 48,67\% em 2006 (com base no faturamento) e de 67,38\% em 2002 para 45,41\% em 2006 (com base no número de empregados). O índice HH diminuiu de 1.666,03 em 2001 para 849,18 em 2006(com base no número de empregados).

A queda na concentração indica um aumento na concorrência no setor. Entretanto, foram identificadas algumas barreiras à entrada na indústria que podem limitá-la, como a necessidade de um elevado investimento inicial, a capacidade instalada das empresas em atividade e o difícil acesso aos canais de comercialização.

Sobre a diferenciação do produto e a diversificação da produção, constatou-se que existe uma enorme variedade de produtos dentro do mesmo mercado, com várias formas de preparos, 
formatos e sabores. Com relação à diversificação da produção, a pesquisa detectou que ela também ocorre, uma vez que 36\% das empresas atuavam na produção de biscoitos em 2007 e as empresas vendem massas preparadas (lasanhas, pizzas, nhoques etc.).

A integração vertical é baixa na indústria de massas alimentícias do Rio Grande do Sul, uma vez que apenas uma das 14 empresas produzfarinha de trigo, integração vertical para trás, e quatro empresas tem pontos de venda direta ao consumidor (29\%), integração vertical para frente.

A conduta das empresas é caracterizada na pesquisa pelos gastos em P\&D, pela adoção de contratos e pelas estratégias de Porter e de Mintzberg. Os resultados mostram que o gasto em P\&D é baixo (36\% das empresas gastam, em média, 0,7\% das vendas) e que 50\% dos produtores de massas realizam contratos com os fabricantes de farinha de trigo. Quanto às estratégias, concluiu-se que a diferenciação do produto e a produção com custos mais baixos, estratégias de Porter, e a qualidade do produto,estratégia de Mintzberg, são as mais praticadas pelos produtores de massas.

O desempenho da indústria normalmente decorre da conduta das empresas. Como a lucratividade dos produtores de massas está em queda, com redução nos preços do principal produto, massas secas, e as principais empresas estão perdendo participação no mercado, fica evidente que as estratégias não estão sendo suficientes para melhorar o desempenho e que as ações são passivas, no sentido de que os agentes apenas procuram se adequar ao mercado onde atuam.

Finalizando, pode-se afirmar que estudo proporciona duas contribuições importantes, teórica e gerencial. No campo teórico, o trabalho mostra que a utilização conjunta das teorias amplia a capacidade de entendimento e permite detectar um maior número de ações dos produtores. No campo gerencial, a contribuição está relacionada ao diagnóstico da indústria de massas alimentícias do Rio Grande do Sul, o qual serve de alerta aos produtores pela debilidade que o setor deixa transparecer, especialmente pela falta de estratégias robustas, capazes de influenciar positivamente nos resultados.

\begin{abstract}
The research evaluates the structure, conduct and performance of the pasta industry the State of Rio Grande do Sul in the period between 2001 and 2007. The theoretical base used in the analysis was the structure-conduct-performance (SCP) model and the strategies by Porter and Mintzberg. The results for the structure of the industry shows that: the industrial concentration declines, production is diversified and differentiated and, that it exists barriers to entry that are important to the ones who ingress in the sector, as excess capacity of established companies, the value of initial capital and access to marketing channels. In conduct, differentiation and quality are the most used. The industry performance is also getting worst because even with an increase in production the profitability is dropping and the companies are losing market share.
\end{abstract}

Key-words: pasta industry; strategies; industrial structure.

\title{
Referências
}

ABIMA. Associação brasileira das indústrias de massas alimentícias. Disponível em: $<$ http://www.abima.com.br/est_mnacional.html>. Acesso em: 15 mai. 2007. 
BEM, J. S. Estrutura - conduta - desempenho de mercado das indústrias. Análise, Porto Alegre, v. 1, n. 5 , p. 523 - 538, 1991.

CARLTON B.; PERLOFF, J. Modern industrial organization. Harper Collins, 1990.

CASTELlS, M. A sociedade em rede - a era da informação: economia, sociedade e cultura. 2. ed. São Paulo: Paz e Terra, 1999.

FARINA, E. M. M. Q. Moinho Pacífico: ajustamentos e desafios do livre mercado. In: SEMINÁRIO INTERNACIONAL DE AGRIBUSINESS, 3, 1993, São Paulo. Anais... SãoPaulo: PENSA/FEA/USP, 1993.

FARINA, E. M. M. Q. Competitividade: mercado, estado e organizações. São Paulo: Singular, 1997.

FIERGS. Federação das indústrias do rio grande do sul. Disponível em: http://www.fiergs.com.br/cadastroindustrial. Acesso em: 28 jun. 2007.

IPEA. Instituto de Pesquisa Econômica Aplicada. Competitividade no agribusiness brasileiro. São Paulo, v. II. 1998. $181 \mathrm{p}$.

KON, A. Economia industrial. São Paulo: Nobel, 1994.

LEITE, A. L. Concentração e desempenho competitivo no complexo industrial de papel e celulose 1987-1996. 1998. 99f. Dissertação (Mestrado em Engenharia de Produção) - Universidade Federal de Santa Catarina, Florianópolis.

MORAES, M. A. A indústria de madeira preservada no Brasil: um estudo de sua organização industrial. Piracicaba, 1996. 154p. Dissertação de Mestrado -Escola Superior da Agricultura “Luiz de Queiroz" - ESALQ / USP, Piracicaba.

MARION FILHO, P. J. A evolução e a organização recente da indústria de móveis nos estados de Santa Catarina e Rio Grande do Sul. 1997. 151f. Tese (Doutorado em Economia Aplicada) - Escola Superior da Agricultura "Luiz de Queiroz" - ESALQ / USP, Piracicaba.

MILLER, A.; DESS, G. Assessing Porter's (1980) model in terms of its generalizability, accuracy and simplicity.Journal of Management Studies, v. 30, n. 4, p.553 - 585, Jul. 1993.

cross'ref

MINTZBERG, H. Generic strategies: toward a comprehensive framework, advances in strategic management. JAI Press Greenwich - CT, v.5 p.1-67, 1988.

PORTER, M. E. Competitive strategy: techniques for analysing industries and competitors. New York: Free Press, 1980.

PORTER, M. E. Estratégia competitiva. técnicas para analise de indústrias e concorrência. 7. ed. Rio de Janeiro: Campus, 1986.

RESENDE, M.; BOFF, H. Concentração industrial. In: KUPFER, D.; HASENCLEVER, L. Economia industrial: fundamentos teóricos e práticas no Brasil. Rio de Janeiro: Campus, 2002.

SCHERER, F. M.; ROSS, D. Industrial market structure and economic performance. 3. ed. Chicago: Raud Mc Nally e Co, 1990.

SILVA, J. F.; CARNEIRO, J. M. T.; CAVAlCANTI, M. A. D. F. Impactos da privatização sobre as estratégias competitivas de empresas de petróleo: um estudo de caso. RAE-eletrônica, v. 2, n. 2, jul./dez. 2003.

USDOJ.United States Department of Justice. The Hirschman - Herfindahl Index, In: HORIZONTAL MERGER GUIDELINES, 1997.

ZAEYEN, A. Estrutura e desempenho do setor de papel e celulose no brasil. 1986. 99f. Dissertação (Mestrado em Economia) - Universidade Federal do Rio de Janeiro, Rio de Janeiro. 


\section{Dados dos autores:}

Nome completo: Vitor Francisco Dalla Corte

Filiação Institucional: Universidade Federal do Rio Grande do Sul

Função ou cargo ocupado: Doutorando em Agronegócio

Endereço para correspondência (bairro, cidade, estado, país e CEP): Rua General Lima e Silva, 1509, ap 402; Cidade Baixa; Porto Alegre; CEP: 90050-100

Telefone para contato: (55) 9163-5720

e-mail: vitordallacorte@gmail.com

Nome completo: Pascoal José Marion Filho

Filiação Institucional: Universidade Federal de Santa Maria

Função ou cargo ocupado: Professor

Endereço para correspondência (bairro, cidade, estado, país e CEP): Rua Marechal Floriano

Peixoto, 1750, sala 603; Santa Maria-RS; CEP: 97015-372

Telefone para contato: (55) 9914-8323

e-mail: pascoaljmarion@yahoo.com.br

Recebido para publicação em: 09/09/2010

Aceito para publicação em: 08/10/2010 